\title{
Soil Particle-Size Distribution and Soil Infiltration Characteristics of Different Vegetation Communities in a Typical Mountainous Region of China
}

\author{
Ranran Ren ${ }^{1,2}$, Jiangbao Xia ${ }^{2 *}$, Yongqiang Zhang ${ }^{1}$, Tao Zhang ${ }^{1}$, \\ Xia Liu ${ }^{3}$, Shuyong Zhang ${ }^{1 * *}$
}

${ }^{1}$ Key Laboratory of Agricultural Ecology and Environment, Forestry College, Shandong Agricultural University, Taian, China

${ }^{2}$ Binzhou University, Shandong Key Laboratory of Eco-Environmental Science for Yellow River Delta, Binzhou, China ${ }^{3}$ Jiangsu Key Laboratory of Soil and Water Conservation and Ecological Restoration, Collaborative Innovation Center of Sustainable Forestry in Southern China of Jiangsu Province, Forestry College of Nanjing Forestry University, Nanjing, China

Received: 28 April 2018

Accepted: 10 September 2018

\begin{abstract}
In order to explore the improving effect and mechanisms of vegetation communities on soil structure and infiltration processes, we used fractal scaling theory to analyse soil particle-size distribution (PSD), soil dimension and soil infiltration for seven vegetation communities in the Dabie mountainous region of central China. The results showed that coniferous and broad-leaved mixed forests (PQ) had a higher function of meliorating soil particle structure and infiltration capability than broad-leaved forests (PC and QA) and coniferous forests (PD). In general, the amounts of silt and clay increased under PQ, $\mathrm{PC}$ and QA vegetation communities, whereas fine sand content decreased, resulting in higher values for soil total porosity and capillary porosity. For shelter forests, the infiltration rate was higher than other vegetation communities. The overall fractal dimensions of PSD ranged from 2.071 to 2.430 , and the fractal dimensions of PQ, PC, QA and PD in shelter forests were far higher (mean value of 2.312) than those of the others. There was significant positive correlation between the fractal dimension and the amount of silt and clay $(\mathrm{R}=0.815)$, and negative correlation with fine sand $(\mathrm{R}=-0.549)$. There was also a strong linear positive relationship between the fractal dimension and the soil's infiltration rate. Correlations of the fractal dimension with the soil infiltration capability provided strong evidence that vegetation communities enhanced the soil fractal dimension by increasing the amounts of silt and clay, thereby improving both aggregate structure and pore structure and enhancing the degree of soil texture
\end{abstract}

*e-mail: xiajb@163.com

**e-mail: zhsy@sdau.edu.cn 
uniformity and infiltration capacity. This study demonstrates that fractal dimension analysis may be used to quantify differences in PSD and soil infiltration capability better; furthermore, the results can provide a reference for scientific selection and the distribution of plant types that will support soil and water conservation.

Keywords: soil fractal dimension; soil infiltration capability; soil particle-size distribution; vegetation communities

\section{Introduction}

Soil is a porous medium that has different particle compositions and is made of solid components with irregular shapes and pores connected in a certain form [1-2]. The soil structure parameters, including soil particle diameter, bulk, and soil pore and quantity, have a certain self-similar structure and some fractal characteristics. Studies have shown that fractal theory, a popular approach in recent years, has offered a new means of quantifying soil structure, soil porosity, and soil permeability [3-10]. Fractal theory has been applied to various geological phenomena that display large, scale-invariant and self-similar characteristics [11-14]. Fractal theory has also been applied to quantify the process of fragmentation based on a power law relationship between the number of soil grains and grain size [15]. In particular, fractal theory has been shown to be an appropriate means of modeling the fractal dimension of soil particle-size distribution (PSD) and pore structure to describe soil textures, its structural distribution and its uniformity [16-20].

The fractal dimension of PSD was calculated using many methods in previous works. Investigators evaluated the interpretation of number-size distributions and found that a number-size relationship did not necessarily imply a fractal structure, as had previously been assumed [21]. Furthermore, because of the errors introduced by assumptions regarding the grain size and density using the number-based approach, a massbased distribution was developed to estimate the fractal dimension of PSD. In their work, the limits of fractal behavior and the applications of particle-size distributions were developed, deriving fractal scaling relationships for both the soil grains' mass and number [2]. For studying the effects of different land use ways on soil particles and solving the problems of the complex soil morphology process, we looked at the contents of the soil particle size of slope field. Soil clay content was found to have a significantly positive relationship with the correlation coefficient of fractal dimension of soil particles [22]. However, some researchers have found that a single fractal dimension was insufficient to interpret the complete scale of particle-size distribution data on soil grain size distributions obtained from soils composed predominantly of silt and clay [23]. They suggested that, except under very restrictive conditions, particle-size distributions in nature should display multifractal behavior. At present, the Yangpeiling and AR methods are commonly used [1, 24]. The Yangpeiling method [24] uses the quality distribution replacing quantity distribution and then derives the relationship between soil particle quantity distribution and the fractal dimension using the critical method. However, the AR method [1] derives the relationship among soil particle quantity with size and the fractal dimension using the integration method. The Yangpeiling method calculates the fractal dimension of PSD, which could better describe soil particle size and the well-proportioned degree of soil textures and is calculated directly through data on general PSD. However, the AR method calculates the fractal dimension of the soil particle surface, which is better able to describe quantitatively the variation in the soil textures and is also calculated according to the measurement results of PSD after revision [25].

To date, many studies have applied multi-fractal analysis of PSD to different land-use patterns and vegetation types, and to the relationship among the fractal dimensions of soil particles with soil type, soil texture, soil density, soil moisture and soil nutrient content [26-31]. In the past few decades, some vegetation communities in the Dabie Mountain region in central China have been transformed from protected forest areas to commercial forests, croplands, or shrub-grassland areas for grazing, and much of the forest has been destroyed due to economic growth and the exploitation of natural resources. Although many studies have revealed the potential of fractal dimensions for quantitatively describing soil physical properties and fertility characteristics, studies on the relationship between fractal dimensions and soil infiltration have been lacking. The soil infiltrating quality is an important index for evaluating the functions of soil and water conservation, and the affected water conservation capacities of soils directly. The better the soil infiltrating quality, the faster the precipitation is infiltrated; by contrast, the precipitation is lost through surface runoff, so the quantitative research between the two measures was significant for applying fractal dimensions to describing soil infiltration. At present, few studies have applied fractal theory to determine the influence of different vegetation communities or land-use patterns on PSDs for similar soils. Furthermore, to date, no studies have been published that investigate the relationship between the fractal dimension of PSD and soil infiltration under different vegetation communities or land-use patterns in the Dabie region. In this paper, the fractal scaling theory of the Yangpeiling method was used to 
analyze PSD, the soil dimension and soil infiltration for seven different vegetation communities with similar soil types; meanwhile, the relationships between the fractal dimension and soil grain and soil infiltration capability were evaluated. The objectives of this work are to assess the effects of vegetation communities or different land use patterns on fractal characteristics and soil infiltration, to reveal its fractal mechanism and the relationship between the fractal dimension and soil infiltration rate. We can grasp the causes of soil erosion in the Dabie area, quantitatively evaluate the degree of degradation of different vegetation types, and the results provided a basis for rational selection and allocation of soil and water conservation plant types and vegetation restoration in this area.

\section{Materials and Methods}

\section{Study Area Description}

The study was conducted at the forestry farm in Tongbai County, located in the hinterland of the Dabie Mountain area in Henan Province of central China. The geographical coordinates are $31^{\circ} 50^{\prime} \mathrm{N}$ and $115^{\circ} 02^{\prime} \mathrm{E}$. It belongs to the north-subtropical zone with a monsoon climate. The average annual temperature is about $14.3 \pm 0.6^{\circ} \mathrm{C}$. The total sunlit time is about $2,320 \mathrm{~h}$, and the frostless season is about 200 days. The average annual evaporation is $960 \mathrm{~mm}$, with more than $73 \%$ occurring between May and June. The average annual precipitation is $920 \mathrm{~mm}$, and more than $60 \%$ of it occurs mainly between June and September. The parent rock material is mainly granite-gneiss. Brown soil and cinnamon soil are the main soil types, soil texture is sandy soil and sandy loam, and they account for more than $75 \%$ of the utilizable land area. Low mountains and hills are the main landform types and account for more than $80 \%$ of the total area. The altitude above sea level is between $800 \mathrm{~m}$ and $1,000 \mathrm{~m}$. Soil and water loss in this area is severe, and the area of soil erosion is more than $69.9 \%$ of the total land area. Deciduous broadleaved mixed forest is the zonal vegetation type in this region. The common types of arboreal vegetation in the area include Pinus densiflora, Quercus acutissima, Robinia pseudoacacia, Platycladus orientalis, Castanea mollissima and Crataegus pinnatifida; the shrub vegetation mainly includes Lespedeza bicolor and Vitex negundo heterophylla; the herbage vegetation mainly includes Poa annua, Roegneria kamoji, Artemisia argyi and Rubus parvifolius.

\section{Vegetation Community Investigation}

In the study region, seven typical vegetation communities were selected according to the four types of land use (Table 1). The seven typical vegetation communities were Pinus densiflora pure forest (PD), Quercus acutissima pure forest (QA), Populus cathayana pure forest (PC), Pinus densiflora and Quercus acutissima mixed forest (PQ), Castanea mollissima pure forest (CM), Zea mays (ZM), and Scrub herbage (SH). The first four vegetation communities (PD, QA, PC and $\mathrm{CM}$ ) were in shelter forest areas, $\mathrm{CM}$ was in an economic forest area, ZM was under cropland production, and $\mathrm{SH}$ represented shrub-grassland areas that were used for comparison. All of the vegetation communities for the study were mainly located on middle-slope areas facing the south with the same altitude and density. The other characteristics that were investigated, such as slope, forest age, diameter at breast height (DBH), tree height, crown width and the code used in this paper are referred to in Table 1; the soil's chemical and physical properties in seven vegetation communities are referred to in Table 2 .

\section{Sampling and Processing}

Three sample plots were selected as sampling units in each of the seven vegetation communities, with each plot unit covering an area of approximately $400 \mathrm{~m}^{2}(20 \mathrm{~m} \times 20 \mathrm{~m})$. Five soil sampling sites were

Table 1. Structure investigation of seven vegetation communities in the study area.

\begin{tabular}{|c|c|c|c|c|c|c|c|c|c|}
\hline Land-use type & $\begin{array}{l}\text { Vegetation } \\
\text { community }\end{array}$ & Code & Slope $\left(^{\circ}\right)$ & $\begin{array}{l}\text { Forests age } \\
\quad \text { (year) }\end{array}$ & $\begin{array}{l}\mathrm{DBH} \\
(\mathrm{cm})\end{array}$ & $\begin{array}{c}\text { Tree } \\
\text { height } \\
(\mathrm{m})\end{array}$ & $\begin{array}{l}\text { Crown } \\
\text { width } \\
(\mathrm{m})\end{array}$ & $\begin{array}{l}\text { Canopy } \\
\text { density }\end{array}$ & $\begin{array}{l}\text { Management } \\
\text { type }\end{array}$ \\
\hline \multirow{4}{*}{$\begin{array}{c}\text { Shelter forest } \\
\text { land }\end{array}$} & P. densiflora & PD & $14.4 \pm 0.15$ & 30 & $13.2 \pm 1.2$ & $8.2 \pm 0.9$ & $3.2 \times 2.6$ & $0.92 \pm 0.1$ & \multirow{4}{*}{ Protection } \\
\hline & Q. acutissima & QA & $14.3 \pm 0.12$ & 32 & $8.0 \pm 1.7$ & $6.3 \pm 1.4$ & $2.8 \times 2.0$ & $0.78 \pm 0.08$ & \\
\hline & P. cathayana & $\mathrm{PC}$ & $13.2 \pm 0.10$ & 28 & $8.7 \pm 1.1$ & $7.2 \pm 2.1$ & $2.9 \times 2.1$ & $0.88 \pm 0.09$ & \\
\hline & $\begin{array}{l}\text { P. densiflora and } \\
\text { Q. acutissima }\end{array}$ & PQ & $17.4 \pm 0.08$ & 32 & $4.5 \pm 2.1$ & $3.1 \pm 1.8$ & $1.3 \times 2.4$ & $0.91 \pm 0.05$ & \\
\hline $\begin{array}{l}\text { Economic } \\
\text { forest land }\end{array}$ & C. mollissima & $\mathrm{CM}$ & $11.1 \pm 0.13$ & 27 & $15.6 \pm 1.7$ & $6.3 \pm 2.0$ & $5.1 \times 6.3$ & $0.67 \pm 0.07$ & \multirow{2}{*}{ cultivation } \\
\hline Crop land & Zea mays & ZM & $11.3 \pm 0.07$ & - & - & - & - & - & \\
\hline $\begin{array}{l}\text { Shrub } \\
\text {-grassland }\end{array}$ & Scrub herbose & $\mathrm{SH}$ & $14.2 \pm 0.10$ & - & - & - & - & $0.75 \pm 0.15$ & Protection \\
\hline
\end{tabular}


Table 2. Soil chemical and physical properties in seven vegetation communities.

\begin{tabular}{|c|c|c|c|c|c|c|c|}
\hline Land-use type & $\begin{array}{c}\text { Vegetation com- } \\
\text { munity }\end{array}$ & $\mathrm{pH}$ & $\begin{array}{c}\text { Organic matter } \\
(\mathrm{mg} / \mathrm{kg})\end{array}$ & $\begin{array}{c}\text { Soil } \\
\text { moisture }(\%)\end{array}$ & $\begin{array}{c}\text { Bulk density } \\
\left(\mathrm{g} / \mathrm{cm}^{3}\right)\end{array}$ & $\begin{array}{c}\text { Capillary } \\
\text { porosity }(\%)\end{array}$ & $\begin{array}{c}\text { Non-capillary } \\
\text { porosity }(\%)\end{array}$ \\
\hline \multirow{3}{*}{$\begin{array}{c}\text { Shelter forest } \\
\text { land }\end{array}$} & P. densiflora & $7.13 \pm 0.02$ & $4.75 \pm 0.05$ & $10.92 \pm 0.15$ & $1.33 \pm 0.07$ & $28.6 \pm 0.8$ & $15.1 \pm 0.2$ \\
\cline { 2 - 8 } & Q. acutissima & $7.20 \pm 0.05$ & $4.90 \pm 0.08$ & $14.36 \pm 0.10$ & $1.23 \pm 0.04$ & $37.8 \pm 0.7$ & $12.9 \pm 0.2$ \\
\cline { 2 - 8 } & $\begin{array}{c}\text { P. cathayana } \\
\text { Q. densiflora and }\end{array}$ & $7.17 \pm 0.03$ & $5.43 \pm 0.07$ & $10.50 \pm 0.21$ & $1.19 \pm 0.05$ & $39.4 \pm 0.9$ & $14.1 \pm 0.1$ \\
\hline $\begin{array}{c}\text { Economic } \\
\text { forest land }\end{array}$ & C. mollissima & $7.04 \pm 0.04$ & $5.87 \pm 0.04$ & $12.60 \pm 0.17$ & $1.16 \pm 0.04$ & $41.1 \pm 1.3$ & $11.5 \pm 0.7$ \\
\hline Crop land & Zea mays & $7.47 \pm 0.06$ & $4.26 \pm 0.08$ & $14.07 \pm 0.10$ & $1.51 \pm 0.02$ & $21.4 \pm 0.5$ & $17.0 \pm 0.9$ \\
\hline $\begin{array}{c}\text { Shrub } \\
\text { grass land }\end{array}$ & Scrub herbose & $7.26 \pm 0.05$ & $3.35 \pm 0.07$ & $18.01 \pm 0.18$ & $1.28 \pm 0.02$ & $26.0 \pm 1.1$ & $16.6 \pm 0.8$ \\
\hline
\end{tabular}

located in each plot unit at equidistant positions along the length of the diagonal sampling line. The soil type was brown soil in each plot. Soil infiltration and PSD were measured at each soil sampling site.

\section{Measurement of PSD and Calculating the Fractal Dimension}

The quality distribution of the soil particle size was measured by a nest of ASTM sieves according to the procedure described in a previous study [32]. Soil samples were collected from the $0-40 \mathrm{~cm}$ soil layer from all of the plots. Five samples were collected from each plot unit using a soil sampling auger and then mixed uniformly for PSD analysis. A total of 15 samples were taken per vegetation community. Initially, soil samples were air-dried and machinesieved through a $2-\mathrm{mm}$ screen to remove roots and other debris. The soil samples were successively passed through the standard sieves with apertures of $1.00 \mathrm{~mm}$, $0.50 \mathrm{~mm}, 0.25 \mathrm{~mm}, 0.10 \mathrm{~mm}$ and $0.05 \mathrm{~mm}$ using a ZBSX-92A type standard vibrating machine produced by the Institute of Soil Science, Chinese Academy of Sciences. The machine sways 221 times and vibrates 147 times per minute; the swaying distance is $25 \mathrm{~mm}$, and the power of the electrical machinery is $0.37 \mathrm{kw}$. Finally, the PSD was described in terms of the percentage of gravel $(1.0 \sim 2.0 \mathrm{~mm})$, coarse sand $(0.25 \sim 1.0 \mathrm{~mm})$, fine sand $(0.05 \sim 0.25 \mathrm{~mm})$ and clay-silt particles $(<0.05 \mathrm{~mm})$. Although the soil samples were largely composed of different sand fractions and gravel, each PSD sample was measured in duplicate to minimize the underestimation of primary silt and clay particles and achieve good reproducibility.

The fractal dimension of PSD was calculated according to the Yangpeiling method, using the following equation [25]:

$$
D=3-\frac{\lg \left(w_{i} / w_{0}\right)}{\lg \left(d_{i} / d_{\max }\right)}
$$

...where $D$ is the fractal dimension of PSD, $d_{i}$ is the mean particle diameter $(\mathrm{mm})$ of the $i$ th particle-size class, $d_{\text {max }}$ is the mean diameter $(\mathrm{mm})$ of the largest particle, $w_{i}$ is the cumulative mass $(\mathrm{g})$ of the soil particles of $i$ th size less than $d_{i,}$ and $w_{0}$ is the total mass of the soil sample, respectively. The mean particle diameter is taken as the arithmetic mean of the upper and lower sieve sizes.

During the calculating process, the values of $\lg \left(d_{i} / d_{\operatorname{ma}}\right)$ and $\lg \left(w_{i} / w_{0}\right)$ of each soil particle fraction $\left(d_{i}\right)$ were first calculated, then the scatter plot was made with $\lg \left(d_{i} / d_{\max }\right)$ as the $\mathrm{X}$ coordinate and the $\lg \left(w_{1} / w_{0}\right)$ as the $\mathrm{Y}$ coordinate. Slope $(K)$ was obtained by straight-line regression, and finally the fractal dimension of soil particle in each vegetation community was calculated by the following equation: $D=3-K$.

\section{Observation and Modelling of Soil Infiltration Process}

The soil infiltration process was determined by a Guelph permeameter (2800K1type, SEC, USA) with three replicates of each sample point unit. So as to find models suitable for the prediction of water infiltration in seven vegetation communities, using SPSS statistical analysis software, infiltration rates simulated by three popular infiltration models, the Philip model (1), the Horton model (2), and the common empirical model (Power function) (3), were compared by using those observed results. Soil infiltration was simulated using the following three models: the Philip model (1), the Horton model (2) and the common empirical model (Power function) (3). Next, some infiltration characteristic parameters, such as the initial infiltration rate and the steady infiltration rate, were obtained by simulation. The expressions and parameter meanings of three models were found to be:

$$
f=\frac{\sqrt{s t}}{2}+A
$$


...where $\mathrm{f}$ is the infiltration rate $(\mathrm{mm} / \mathrm{min}), \mathrm{S}$ is the water absorption rate $\left(\mathrm{m} / \mathrm{min}^{1} / 2\right)$, and $\mathrm{A}$ is a constant equal to the steady infiltration rate $(\mathrm{mm} / \mathrm{min})$;

$$
f=f_{c}+\left(f_{0}-f_{c}\right) e^{-k t}
$$

... where $f$ is the infiltration rate $(\mathrm{mm} / \mathrm{min}), f_{0}$ is the initial infiltration rate $(\mathrm{mm} / \mathrm{min}), f_{\mathrm{c}}$ is the steady infiltration rate $(\mathrm{mm} / \mathrm{min}), \mathrm{t}$ is the soil infiltration time ( $\mathrm{min})$, and $\mathrm{k}$ is an empirical constant; and

$$
f=a t^{-n}+b
$$

...where $\mathrm{f}$ is the infiltration rate $(\mathrm{mm} / \mathrm{min}), \mathrm{a}, \mathrm{b}$ and $\mathrm{n}$ are empirical constants, $b$ is equal to the steady infiltration rate $(\mathrm{mm} / \mathrm{min}), \mathrm{n}$ is a decaying constant, and $\mathrm{t}$ is the soil infiltration time (min).

\section{Results}

\section{PSD among the Different Vegetation Communities}

Table 3 shows the quality percentage of different PSDs among the seven vegetation communities. As shown in Table 3, the predominant soil particle size was found to be coarse sand. The percentages of coarse sand were between $39.3 \%$ and $47.3 \%$, with a mean value of $43.3 \%$. Fine sand was the second-most abundant particle type, ranging between $21.5 \%$ and $37.4 \%$, with a mean value of $27.3 \%$. The content of gravel and silt-clay was relatively lower, with the percentage of gravel ranging between $10.2 \%$ and $21.3 \%$ (mean value of $16.8 \%$ ) and silt-clay ranging from $9.2 \%$ to $17.3 \%$ (mean value of $12.7 \%)$. There were significant differences $(P<0.05)$ in other particle-size distributions except for gravel and silt-clay. The content of sand was much higher than that of silt-clay, which is indicative of skeletal-type soils that are commonly found in rocky mountainous terrain in northern China [33].

In addition, the greatest differences in PSD among the seven vegetation communities were in the percentages of silt-clay. The sequence was as follows: QA $\quad(17.3 \%)>P Q \quad(16.8 \%)>P C \quad(15.5 \%)>P D$ $(10.2 \%)>\mathrm{SH} \quad(9.9 \%)>\mathrm{CM} \quad(9.8 \%)>\mathrm{ZM} \quad(9.2 \%)$. There was a significant difference $(P<0.05)$ among the other plant communities except for $\mathrm{PD}, \mathrm{SH}$, and $\mathrm{CM}$. There were also greater differences in the percentages of fine sand content among the seven vegetation communities, with a difference value of $15.9 \%$. The sequence was as follows: $\mathrm{ZM}(37.4 \%)>\mathrm{SH} \quad(30.2 \%)>\mathrm{CM}>\mathrm{D} \quad(27.3 \%)>\mathrm{PQ}$ $(24.3 \%)>$ QA $\quad(22.8 \%) \mathrm{VPC} \quad(21.5 \%)$. Whereas there was not a significant difference $(P>0.05)$ among the latter three plant communities (PQ, QA and PC), there was a significant difference $(P<0.05)$ with the other plant communities. Moreover, the differences in the soil particle size fractions for PC, QA and PQ were characterized by a considerable increase in silt-clay particle size fractions, and were accompanied by a decrease in the fine sand fraction, indicating that the soils in the shelter forest region (PC, QA and PQ) have become more fine-textured over time. This suggests that the changes in the protection management of these areas have accelerated the increase of clay and silt as a result of increased canopy and residue cover, which would otherwise serve to lessen the rainfall impact and overland flow, and thereby also decrease soil erosion.

\section{Fractal Dimension of PSD for Different Vegetation Communities}

Fig. 1 shows calculated fractal dimension values for PSD using the Yangpeiling method for each of the seven vegetation communities. According to an analysis of variance, there were significant differences $(P<0.05)$ in the fractal dimension among certain types of plant communities. Overall, fractal dimensions varied among

\begin{tabular}{|c|c|c|c|c|c|c|c|c|}
\hline \multirow{3}{*}{ Land use type } & \multirow{3}{*}{$\begin{array}{l}\text { Vegetation } \\
\text { communities }\end{array}$} & \multirow{3}{*}{ Code } & \multicolumn{6}{|c|}{ Soil particle-size fractions (mm) } \\
\hline & & & \multirow{2}{*}{$\begin{array}{l}\text { Gravel } \\
2.0-1.0\end{array}$} & \multicolumn{2}{|c|}{ Coarse sand } & \multicolumn{2}{|c|}{ Fine sand } & \multirow{2}{*}{$\begin{array}{c}\text { Silt-clay } \\
<0.05\end{array}$} \\
\hline & & & & $1.0-0.5$ & $0.5-0.25$ & $0.25-0.1$ & $0.1-0.05$ & \\
\hline \multirow{4}{*}{ Shelter forest land } & P. densiflora & PD & $15.2 \pm 0.9$ & $24.9 \pm 0.4$ & $19.2 \pm 1.0$ & $24.5 \pm 1.1$ & $2.8 \pm 0.3$ & $10.2 \pm 0.5$ \\
\hline & Q. acutissima & QA & $20.7 \pm 0.8$ & $26.2 \pm 0.7$ & $15.4 \pm 0.5$ & $16.1 \pm 1.0$ & $6.7 \pm 0.2$ & $17.3 \pm 0.4$ \\
\hline & P. cathayana & $\mathrm{PC}$ & $21.3 \pm 1.6$ & $25.1 \pm 1.1$ & $14.2 \pm 0.4$ & $15.9 \pm 0.7$ & $5.6 \pm 0.2$ & $15.5 \pm 0.5$ \\
\hline & $\begin{array}{l}\text { P. densiflora and } \\
\text { Q. acutissima }\end{array}$ & PQ & $14.8 \pm 0.7$ & $16.2 \pm 0.2$ & $31.1 \pm 0.9$ & $12.4 \pm 0.4$ & $11.9 \pm 0.4$ & $16.8 \pm 1.1$ \\
\hline Economic forest land & C. mollissima & $\mathrm{CM}$ & $17.0 \pm 1.3$ & $23.6 \pm 0.5$ & $17.8 \pm 0.5$ & $23.2 \pm 0.7$ & $4.1 \pm 0.2$ & $9.8 \pm 0.7$ \\
\hline Cropland & Zea mays & $\mathrm{ZM}$ & $10.2 \pm 1.8$ & $25.3 \pm 1.3$ & $20.6 \pm 0.7$ & $28.3 \pm 1.5$ & $9.1 \pm 0.3$ & $9.2 \pm 0.5$ \\
\hline Shrub-grass land & Scrub herbose & $\mathrm{SH}$ & $18.5 \pm 1.1$ & $25.6 \pm 1.4$ & $17.6 \pm 1.3$ & $25.4 \pm 1.4$ & $4.8 \pm 0.4$ & $9.9 \pm 0.5$ \\
\hline
\end{tabular}

Table 3. Quality percentages of different soil particle-size fractions among the seven vegetation communities (\%).

Note: The same particle size was included in the bigger particle size range; for example, the soil that was about $0.5 \mathrm{~mm}$ was included in the particle size of $1.0-0.5 \mathrm{~mm}$, and not $0.5-0.25 \mathrm{~mm}$. 


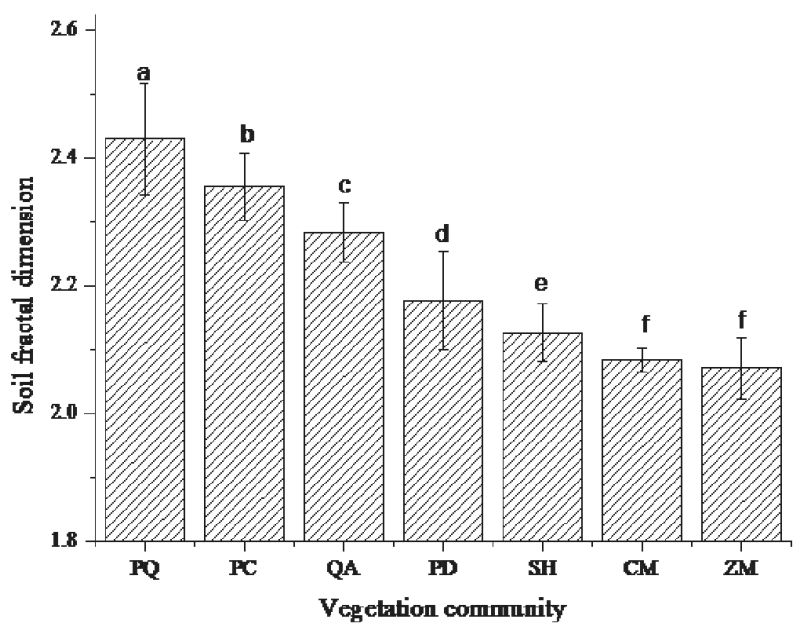

Fig. 1. Fractal dimension of soil particle-size distribution under different vegetation communities. Fractal dimension of soil particle-size distribution under Pinus densiflora pure forest (PD), Quercus acutissima pure forest (QA), Populus cathayana pure forest (PC), Pinus densiflora and Quercus acutissima mixed forest (PQ), Castanea mollissima pure forest (CM), Zea mays (ZM), and scrub herbage (SH); histograms are the mean of at least 15 replicate samples per vegetation community; vertical bars indicate $\pm 1 \mathrm{SE}$ of the mean.

individual plant communities from 2.071 to 2.430 (mean value of 2.218, Fig. 1), representing soils of perhaps lesser quality. The fractal dimensions of four vegetation communities (PQ, PC, QA and PD) for the shelter forest region, with a mean value of 2.312 , were much higher than those of SH, CM and ZM (Fig. 1). There was also a significant difference $(P<0.05)$ in the fractal dimensions for different shelter forest communities, with the highest value of fractal dimensions corresponding to PQ (2.430), followed by PC (2.355), QA (2.284), and PD (2.177).

\section{Relationships between the Fractal Dimension and PSD}

Fig. 2 shows the linear regression analyses between fractal dimension values and the contents of gravel, coarse sand, fine sand, and silt-clay under different vegetation communities. As shown in Fig. 2, the relationships between the fractal dimension and the contents of different soil particle-size fractions had remarkable distinctions. The fractal dimension of PSD had a strong positive correlation with the content of silt-clay (Fig. 2a), $\mathrm{R}=0.815$ ), a negative correlation with the content of fine sand (Fig. 2b), $\mathrm{R}=-0.549$ ), and no correlation based on the content of coarse sand (Fig. 2c), $\mathrm{R}=-0.084$ ) and gravel (Fig. 2d), $\mathrm{R}=0.172$ ). Thus, based on regression analysis, the reflection of the fractal dimension on the content of different particlesize fractions was different, and the soils with higher contents of silt-clay and lower fractions of fine and coarse sand had higher fractal dimension values. The values of the fractal dimension did not appear to be related to the content of coarse sand and gravel. Other studies had obtained similar results in very different landscapes and under contrasting climate conditions [29, 34].

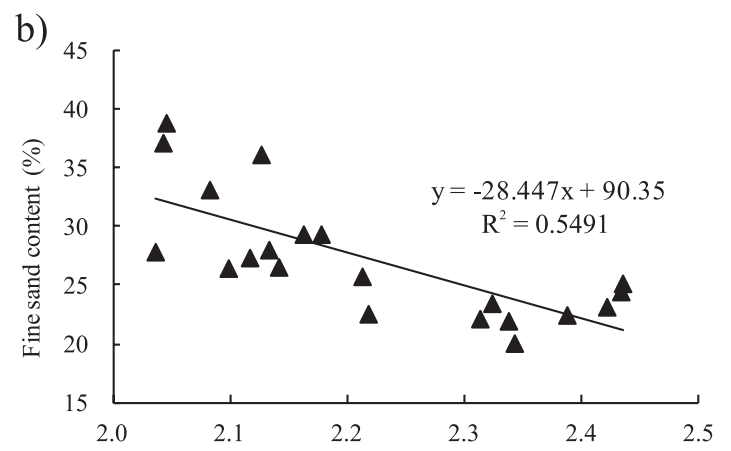

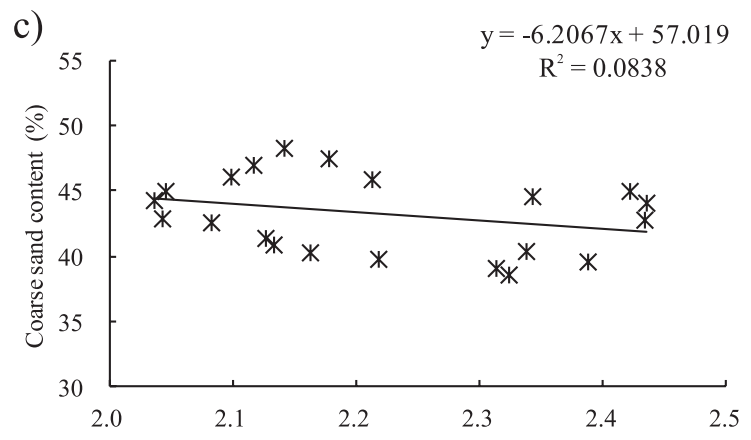

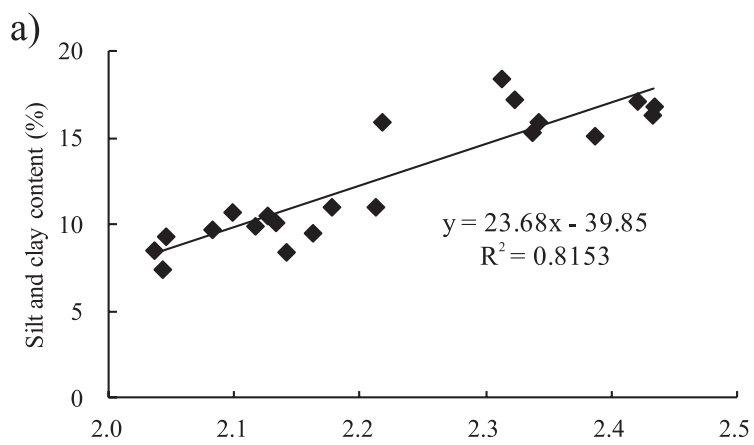

c)

Soil fractal dimension

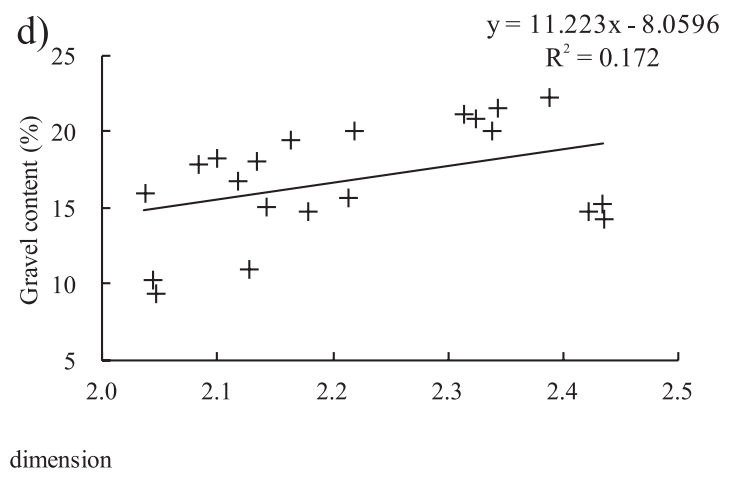

Fig. 2. Relationships between soil fractal dimension and weight percentage of: silt and clay content a), fine sand content b), coarse sand content c) and gravel content d); regression lines were fit using a polynomial expression. 


\section{Soil Infiltration Rates for Different Vegetation Communities}

The actual measurement of the soil infiltration rate under different vegetation communities is referred to in Table 4. As shown in Table 4, there were considerable differences in the initial infiltration rate and steady infiltration rate among the seven vegetation communities. The initial infiltration rate (within $0 \sim 5 \mathrm{~min}, f_{0}$ ) showed an increasing trend among the seven vegetation communities, with PQ (26.64) $>\mathrm{PC} \quad(25.00)>\mathrm{QA}$ (22.55) $>\mathrm{PD}(15.07)>\mathrm{SH}(14.74)>\mathrm{ZM}(13.25)>\mathrm{CM}(12.75)$. Overall, the initial infiltration rate of the shelter forest areas (PC, PQ and QA) was significantly higher as compared with that of the other vegetation community regions. Variation analysis showed significant differences in the soil's initial infiltration rate among the various vegetation communities $(P<0.05)$. However, there was no significant difference between certain groups of plant communities $(P>0.05)$, including 1$) \mathrm{PD}$ and $\mathrm{SH}$, and 2) $\mathrm{ZM}$ and $\mathrm{CM}$. Among the different vegetation communities, mixed forest (PQ) and broad-leaved forest (PC and $\mathrm{QA}$ ) had the higher initial infiltration rates. If we presumed the $f_{0}$ of $\mathrm{CM}$ to be $100 \%$, then the average $f_{0}$ of PC, QA and PQ would be $194.1 \%$, and the $f_{0}$ of SH and PD would be $115.6 \%$ and $118.2 \%$, respectively.

The steady infiltration rate (within 40 70 $\mathrm{min}, f_{\mathrm{c}}$ ) also showed an increasing trend among seven vegetation communities, respectively, with $\mathrm{PQ}$ (9.07) $>\mathrm{PC}$ (8.05) $>$ QA (7.56) $>$ PD (5.54) $>$ SH (4.94) $>\mathrm{CM}(4.86)>\mathrm{ZM}$ (4.53). Furthermore, there was no significant difference between certain groups of plant communities $(P>0.05)$, namely 1) $\mathrm{PC}$ and $\mathrm{QA}$, and 2) $\mathrm{PD}, \mathrm{SH}, \mathrm{CM}$ and $\mathrm{ZM}$. Among the different vegetation communities, the broadleaved mixed forest community had the highest steady infiltration rate, and the broad-leaved forest had a higher steady infiltration rate than the needle-leaved forest, the shrubby grassland of barren hillsides and the economic forest. If we presumed the $f_{\mathrm{c}}$ of ZM to be $100 \%$, then the $f_{\mathrm{c}}$ of PQ would increase by $100.2 \%$, and the average $f_{\mathrm{c}}$ of the broad-leaved forest (PC and QA) would increased by $72.3 \%$. These data indicated that the soil in this area had high infiltration and permeability capability.

\section{Simulating the Soil Infiltration Process}

Three infiltration models - the Horton, the power function and the Philip models - were presented to simulate the soil infiltration process under different vegetation communities, and the simulation results are shown in Table 4. The coefficient of determination $\left(\mathrm{R}^{2}\right)$ of the three models corresponding to different vegetation communities was more than 0.96 , indicating that these three models could reflect the soil infiltration process to a certain extent. However, there was a bigger distinction among the simulation results in terms of the steady infiltration rate (parameter $f_{\mathrm{c}}$ of the Horton model, parameter $B$ of the power function and parameter $A$ of the Philip model). As shown in

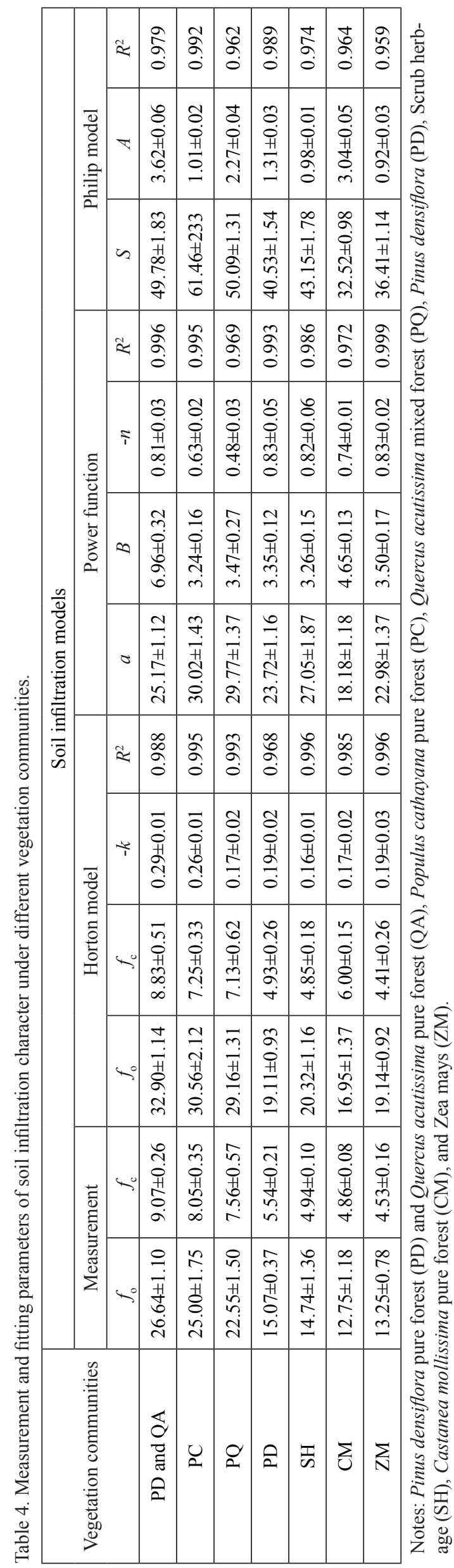


Table 4, the simulation value of parameter $f_{\mathrm{c}}$ of the Horton model was comparatively similar to the measurement; in contrast, the simulation values of the power function and the Philip model were obviously lower than the measurements. These data show that the Horton model was better able to simulate the infiltration process and steady infiltration rate, but the steady infiltration rate that was simulated by either the power function or the Philip model had a big wrap to measurement.

\section{Correlation between Fractal Dimension and Soil Infiltration Rate}

Linear regression analyses were performed to determine the strength of relationships between fractal dimension of soil particle size and soil infiltration rate (Fig. 3). There were significant positive correlations between the fractal dimension and the initial infiltration rate (Fig. 3a), and the stable infiltration rate (Fig. 3b). The fractal dimension of soil particle size had a strong positive correlation with the initial infiltration rate $\left(\mathrm{R}^{2}=0.9037\right)$ and the stable infiltration rate $\left(\mathrm{R}^{2}=0.9229\right)$. Thus, based on regression analysis, the correlation with the steady infiltration rate was stronger than with the initial infiltration rate, which is due to the fractal dimension of PSD reflecting the spatial filling capacity of soil based on the distribution of soil particles [35]. In other words, the smaller the soil particle diameter (i.e., clay, silt, and organic matter), the greater the spatial filling capacity of the soil, which corresponds to higher fractal dimension values of PSD. In addition, as a result of a higher degree of aggregation among the finer soil particles, non-capillary porosity decreases, thereby improving water-holding capacity.

\section{Discussion}

Soils of this nature are classified as multi-gravel coarse sand soils according to the Chinese soil texture classification system [33]. This type of soil has higher rocky sand content because it lacks clay-silt sand and usually has some prominent problems with coarse texture, porous structure, strong water permeability and weak water retention [36-37]. However, shelter forest communities could increase the content of clay-silt sand and reduce the rocky sand content, thereby improving both soil physical structure and water retention. With regards to quantitatively describing soil texture, soil physical properties and fertility characteristics by soil fractal dimension, the existing studies indicated that the fractal dimension of PSD appeared in ascending order, with soil texture changing from coarse to fine [24]. The fractal dimension under different vegetation communities in the Dabie region was about 2.071 2.430 (average 2.218, Fig. 1), and all of the soil particles that were less than that (about 2.60 2.80) had better texture structure and fertility characteristics [38] and belonged to the sandy soil range (about 1.83 2.64) [24]. Although the range of fractal dimension values in this study is relatively low, it is apparent that the plant communities with higher fractal dimension values correspond to those with improved soil conditions. Thus, fractal dimension values based on PSD might provide additional information regarding soil degradation among different plant communities as compared with PSD or soil texture alone. Clearly, the higher the soil fractal dimension in vegetation communities, the stronger the improving effect on soil structure.

The functional mechanism of vegetation communities in improving soil physical structure was related to the essence of soil fractal dimension because the fractal dimension of the soil particle, as the parameter that describes the geometric figure of soil structure, reflected the fill capability of the soil particle to inter-space [39]. Specifically, the smaller the diameter of the soil particle, the higher the fine grain (claysilt sand and organic matters) content. Therefore, soil particles had a stronger fill capability than inter-space and a larger fractal dimension, so it was propitious to form better soil texture and pore structure, and vice versa. This relationship was especially obvious in soil a)

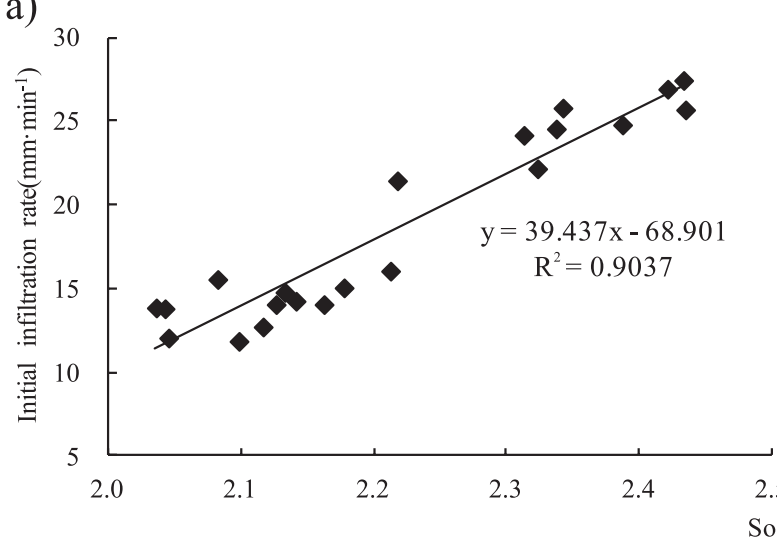

b)

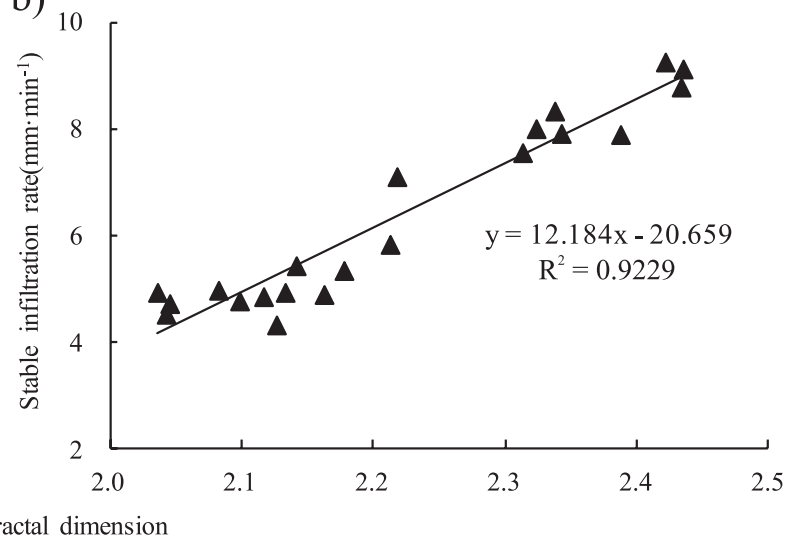

Fig. 3. Relationships between soil fractal dimension and soil initial infiltration rate a) and stable infiltration rate b); regression lines were fit using a polynomial expression. 
with more coarse textures (sandy soil). It was important that the fractal dimension had a positive correlation with silt and clay and a negative correlation with sand content (Fig. 2). Vegetation communities raised the soil fractal dimension by increasing the fine grain content, which was its fractal mechanism for improving the soil physical structure and giving full play to the function of soil and water conservation.

Soil infiltration, an important process in the field water cycle, is influenced by many factors under natural conditions, such as rainfall, ground cover and soil physical structure. However, the infiltration process of the point source, measured in the sufficient water supply, was most strongly influenced by the soil physical structure, such as soil texture, pore structure and soil water content, but has no direct relationship with topographical factors such as gradient and grade length. Therefore, its feature parameter, such as the steady infiltration rate and the initial infiltration rate, could better reflect the effect of vegetation communities on soil hydrologic-physical properties. This study indicated that four shelter forest communities had effects on raising the soil infiltration rate, especially on raising the steady infiltration rate; the conifer and broad-leaved mixed forest had higher effects than the broad-leaved and needle-leaved forest (Table 4), which was probably similar to the results of relevant studies on the effects of different vegetation communities on improving soil infiltration capability [40].

To date, studies referring to the relationship between soil infiltration rate and fractal dimension were lacking. In our study, the soil infiltration rate had an obvious positive relationship with the fractal dimension (Fig. 3), which probably had something to do with the texture structure of the rocky-coarse sand in the study region. In the rocky mountain region, the soil water movement in the soil-rock mixed medium was more complex than that of the homogeneous soil, and the existence of rock fragments and sand grain could increase the curve degree and flow resistance of pores (water movement channels). Therefore, the soil infiltration rate not only depended on the quantity of the soil pores, but also and more importantly on the curve degree and connectivity. Moreover, the vegetation communities could raise the soil fractal dimension (Table 3 and Fig. 1) by reducing the sand content and increasing silt and clay. At the same time, the formation of many aggregate structures was promoted to enhance the connectivity and water permeability of pores, especially non-capillary porosity. This was also the fractal mechanism of vegetation communities for improving the soil infiltration rate in the rocky mountain region.

At present, simulating the soil infiltration process by semi-theoretical and semi-empirical or pure empirical infiltration models on the basis of actual measurements is still an important method for investigating the soil's eco-hydrological function. As compared to existing studies [41], the results - which were simulated by different models for the infiltration process of the same soil texture or the same models for various soil textures - were different, showing that no infiltration model was universally suitable for various soil types [41]. It was correlated with the boundary conditions, the applicable conditions and limitations of different models, as well as the many factors influencing the soil infiltration process. For example, the applicability of the Philip model was weak in our study because it was difficult to adapt the change of soil infiltration in different water content, or the early soil water content was higher in different vegetation communities, which did not satisfy the applicable condition of the Philip model with low initial water content.

\section{Conclusions}

Fractal dimension analyses were used to quantify differences in the particle-size distribution in the Dabie region of China in relation to land degradation caused by human disturbances. The conversion of native forests to commercial forests, cropland and shrub-grassland in the Dabie region has resulted in various levels of soil degradation. Among the different plant communities, shelter forest communities maintained adequate soil structure and quality through litter decomposition and plant root development, which served to enhance the soil's ability to retain water and reduce the transport capacity of overland flow, and thereby had obvious effects on improving the soil's physical properties, fractal dimension and infiltration rate. The order of effectiveness, from greatest to least, was conifer and broad-leaved mixed forest (PQ), broad-leaved forest (PC and QA), and needle-leaved forest (PD). PSDs in other plant communities were characterized by a considerable decrease in soil silt-clay particles, accompanied by an increase in the sand fraction.

Significant linear relationships were found between the fractal dimension and soil particle size and infiltration. There were positive correlations between the fractal dimension and silt-clay sand and soil infiltration, but negative correlations between the fractal dimension and fine sand and coarse sand content. Thus, lower contents of silt-clay and higher sand contents resulted in lower fractal dimension values. The fractal geometry mechanism by which plant communities improved soil fractal structure and infiltration property was to increase the soil fractal dimension by raising the content of fine sand and clay particles, thereby improving aggregate structures, pore structure, soil texture uniformity and infiltration capacity. The results of this study demonstrate that the fractal dimension analysis of PSD offers a useful approach for quantifying and assessing the degree of soil degradation among similar soil types, as affected by different plant communities in the Dabie mountainous region.

Finally, the Horton model was best able to simulate the soil infiltration and stable infiltration rate in the Dabie mountainous region, followed by the power 
function and then, finally, the Philip model. Overall, this study suggests that shelter forest communities are needed to enhance and sustain soil quality in the area and to avoid further soil degradation resulting from land-use changes due to anthropogenic disturbances.

\section{Abbreviations}

CM, Castanea mollissima pure forest; DBH, diameter at breast height; $\boldsymbol{f}_{\mathrm{c}}$, steady infiltration rate; $\boldsymbol{f}_{\mathbf{0}}$, initial infiltration rate; PC, Populus cathayana pure forest; PD, Pinus densiflora pure forest; PQ Pinus densiflora and Quercus acutissima mixed forest; PSD, soil particle-size distribution; QA, Quercus acutissima pure forest; SH, Scrub herbage; ZM, Zea mays

\section{Acknowledgements}

Our work was financed by the National Natural Science Foundation of China (Nos. 31770761 and 31100196), the Science and Technology Projects of Shandong Province (2017GSF17104; 2017CXGC0316), and the Forestry Science and Technology Innovation Project of Shandong Province (LYCX07-2018-38).

\section{Conflict of Interest}

The authors declare no conflict of interest.

\section{References}

1. KRAVCHENKO A., ZHANG R. D. Estimating the soil water retention from particle-size distribution: a fractal approach. Soil Science. 163, 171, 1998.

2. TYLER S.W., WHEATCRAFU S. W. Fractal scaling of soil particle size distributions: analysis and limitations. Soil Science Society of America Journal. 56, 362, 1992.

3. WANG J., ZHANG M., BAI Z., YANG R., GUO L. Multifractal characteristics of reconstructed soil particle in opencast coal mine dump in loess area. Transactions of the Chinese Society of Agricultural Engineering. 30, (4), 230, 2014.

4. PASTÉN D., MUÑOZ V., CISTERNAS A., ROGAN J., VALDIVIA J. A. Monofractal and multifractal analysis of the spatial distribution of earthquakes in the central zone of chile. Physical Review E Statistical Nonlinear \& Soft Matter Physics. 84, (2), 066123, 2011.

5. GUAN X.Y.,YANG P.L., LÜ Y. Relationships between soil particle size distribution and soil physical properties based on multifractal. Transactions of the Chinese Society for Agricultural Machinery. 42, (3), 44, 2011.

6. GAI X.G., H X.L., ZHANG G.C. Different plant communities in Yimeng Mountain Region under the fractal characteristics of soil particles. Shandong forestry science and technology. 40, (2), 9, 2010.

7. SUN Z., WANG Y.B., LIU G.H., GAO Z.Y. Analysis of soil particle size in the process of alpine meadow degradation in permafrost regions based on multiple fractal theory. Glacier permafrost. 37, (4), 980, 2015.

8. LI T., HE B., ZHANG Y., TIAN J., HE X.R., YAO Y, CHEN X.Y. Fractal analysis of soil physical and chemical properties in five tree-cropping systems in southwestern China. Agroforestry Systems. 90, (3), 457, 2016.

9. YANG T., JING H., YAO X., DONG C.P.,YOU ZH., XUE S. Soil Particle Composition and Its Fractal Dimension Characteristics of Different Land Uses in Loess Hilly Region. Research of Soil \& Water Conservation. 23, (3), $1,2016$.

10. ZHAO W.J., CUI Z., MA H. Fractal features of soil particle-size distributions and their relationships with soil properties in gravel-mulched fields. Arabian Journal of Geosciences. 10, (9), 211, 2017.

11. SANSIVERO F., VITO M.D., VITA S.D., MORGAVI D., PEUGINI D., PAREDES J. Fractal fragmentation theory on pyroclastic deposits from Vesuvius and Campi Flegrei: Determining explosive eruptions energy. Congresso SimpSgi-So.ge.i-Aiv. 35, 2015.

12. LU Y., LIU S., WENG L., WANG L., LI Z., XU L. Fractal analysis of cracking in a clayey soil under freeze-thaw cycles. Engineering Geology. 208, 93, 2016.

13. BERTOL I., SCHICK J., BANDEIRA D.H., PAZ-FERREIRO J., VÁZQUEZ E.V. Multifractal and joint multifractal analysis of water and soil losses from erosion plots: a case study under subtropical conditions in santa catarina highlands, brazil. Geoderma. 287, 116, 2017.

14. LIU Z.Q., GAO J.X., TIAN M.R., ZHONG-FEI L.I., WANG Y.P., TONG M.K. Fractal dimension characteristics of soil particle size under different plant communities in ecological restoration area. Chinese Journal of Ecology. 36, (2), 303, 2017.

15. ANITAS E.M. Microscale fragmentation and small-angle scattering from mass fractals. Advances in Condensed Matter Physics. 2015, (11), 501281, 2015.

16. NABIZADEH E., HARCHEGANI H. B. Performance of Eight Mathematical Models in Describing Particle Size Distribution of Some Soils from Charmahal-va-Bakhtiari Province. Journal of Science \& Technology of Agriculture \& Natural Resources. 15, (57), 63, 2011.

17. WANG J., LU X., FENG Y., YANG, R. Integrating multifractal theory and geo-statistics method to characterize the spatial variability of particle size distribution of minesoils. Geoderma. 317, (39), 39, 2018.

18. NEYSHABOURI M.R., AHMADI A., ROUHIPOUR H., ASADI H., IRANNAJAD M. Soil texture fractions and fractal dimension of particle size distribution as predictors of interrill erodibility. Turkish Journal of Agriculture \& Forestry. 35, (1), 95, 2011.

19. FANG X., WANG C., ZHANG R., ZHANG G., XING X., YANG R., ZHAO J. Soil particle size distribution characteristics under different land use types in yinghe watershed of funiu mountain area. Science of Soil \& Water Conservation. 5, (3), 9, 2017.

20. RIENZI E.A., FOX J.F., GROVE J.H., MATOCHA C.J. Interrill erosion in soils with different land uses: the kinetic energy wetting effect on temporal particle size distribution. Catena. 107, (8), 130, 2013.

21. CRAWFORD J.W., SLEEMANT B.D., YOUNG I.M. On the relation between number-size distributions and the fractal dimension of aggregates. European Journal of Soil Science. 44, (4), 555, 1993.

22. REN T.T., WANG X., CHEN W.J., QIU Y. Relationship of soil particles fractal characteristics and clay content under 
different land use ways. Journal of Shenyang Agricultural University. 44, (2), 202, 2013.

23. YI L., MIN L., WEI C., ZHANG J.H. Spatial variability of fractal dimension for soil particle size distribution and particle volume percentage in farmlands. Transactions of the Chinese Society of Agricultural Engineering, volume. 26 (1), 94-102 (9), 2010.

24. YANG P.L., LUO Y.P., SHI Y.C. Fractal features of soils characterized by mass distribution. Chin. Science Bulletin. 38, 1896, 1993.

25. AHMADI A., NEYSHABOURI M.R., ROUHIPOUR H., ASADI H. Fractal dimension of soil aggregates as an index of soil erodibility. Journal of Hydrology. 400 (3-4), 305, 2011.

26. PENG G., XIANG N., LV S.Q., ZHANG G.C. Fractal characterization of soil particle-size distribution under different land-use patterns in the yellow river delta wetland in china. Journal of Soils \& Sediments. 14, (6), 1116, 2014.

27. SONG X., YAN M., Li H. Fractal characteristics of soil particle-size distributions under different landform and land-use types in the loess gully region. Journal of Food Agriculture \& Environment. 11, (3), 2726, 2013.

28. NEYSHABOURI M.R., AHMADI A., ROUHIPOUR H., ASADI H., IRANNAJAD M. Soil texture fractions and fractal dimension of particle size distribution as predictors of interrill erodibility. Turkish Journal of Agriculture \& Forestry. 35, (1), 95, 2011.

29. XU G., LI Z., LI P. Fractal features of soil particle-size distribution and total soil nitrogen distribution in a typical watershed in the source area of the middle dan river, china. Catena. 101 (2), 17, 2013.

30. EACUTE M.C.J., MILTON C.C.C., DENILTON C.G., JOSÉ M.C., MILTON C.C.C., DENILTON C.G., JOSÉ S.N, MARCELO D.R.S., DOUGLAS M.P.S., IVANILDO A.O. Fractal analysis in the description of soil particle-size distribution under different land-use patterns in Southern Amazonas State, Brazil. African Journal of Agricultural Research.11 (23), 2032, 2016.

31. LV Y., GUAN X.Y., RUAN B.Q.,WANG Y.W. Multifractal characteristics of soil particle size distribution under sewage irrigation in different irrigation years. Applied Mechanics \& Materials. 700, 205, 2015.
32. DANE J.H., TOPP G.C., eds. Soil Science Society of America Book Series, No. 5., Part 4. Physical Methods. SSSA, Inc, Madison, WI. 2002.

33. LIN D.Y. Soil Science. Beijing: China Forestry Publishing House. 57-67, 355, 2002.

34. ZHANG Q.L., ZHAN-BIN L.I., GUO-CE X.U., ZHANG T.G., HUANG P.P., ZHANG Y. Soil particle-size distribution and fractal dimension of different land use types in yingwugou small watershed of dan river. Journal of Soil \& Water Conservation. 2, 244, 2013.

35. LEUNG A.K., BOLDRIN D., LIANG T., WU Z.Y., KAMCHOOM V., BENGOUGH A.G. Plant age effects on soil infiltration rate during early plant establishment. Géotechnique, 2017, 1, 2017.

36. ROY P., SREEKESH S. Effect of Land Cover on Soil Particle Size and Organic Carbon in the Plough Layer. Geostatistical and Geospatial Approaches for the Characterization of Natural Resources in the Environment. Springer International Publishing. 2016.

37. XIAO D., SHI Z., LIU X., WANG L., FENG Z. Fractal dimension of soil particle volume in rubber forest of xishuangbanna. Chinese Journal of Tropical Crops. 38 (5), 8173, 2017.

38. WEI X., LI X., WEI N. Fractal features of soil particle size distribution in layered sediments behind two check dams: implications for the loess plateau, china. Geomorphology, 266, 133, 2016.

39. XIA J., GU Z., ZHOU F., LIU J., PENG S. Soil particle fractal dimension and soil moisture physical properties in different forest stands in hilly red soil region. Science of Soil \& Water Conservation. 10 (5), 9, 2012.

40. LI X., FENG G., ZHAO C., SHI F. Characteristics of soil infiltration in the tarim river floodplain. Environmental Earth Sciences. 75 (9), 782, 2016.

41. SHAHSAVAR A.M., PAZIRA E., DADGAR M., GILKES R.J., PRAKONGKEP N. Studying the philip model capability to estimate water infiltration parameters. Proceedings of the 19th World Congress of Soil Science: Soil solutions for a changing world, Brisbane, Australia, 1-6 August, 2010. 